\title{
$\alpha$ - and $\beta$-Adducin polymorphisms affect podocyte proteins and proteinuria in rodents and decline of renal function in human IgA nephropathy
}

\author{
Mara Ferrandi • Daniele Cusi • Isabella Molinari • Lucia Del Vecchio • \\ Cristina Barlassina • Maria Pia Rastaldi • Francesco Paolo Schena • Fabio Macciardi • \\ Carmelita Marcantoni • Dario Roccatello • Luanne L. Peters • Silvia Armelloni • \\ Li Min • Laura Giardino • Deborah Mattinzoli • Claudio Camisasca • \\ Fiorentina Palazzo • Paolo Manunta • Patrizia Ferrari • Giuseppe Bianchi
}

Received: 30 November 2008 / Revised: 20 September 2009 /Accepted: 25 September 2009 / Published online: 17 October 2009

(C) The Author(s) 2009. This article is published with open access at Springerlink.com

\begin{abstract}
Adducins are cytoskeletal actin-binding proteins $(\alpha, \beta, \gamma)$ that function as heterodimers and heterotetramers and are encoded by distinct genes. Experimental and clinical evidence implicates $\alpha$ - and $\beta$-adducin variants in
\end{abstract}

Mara Ferrandi and Daniele Cusi contributed equally to this study.

Electronic supplementary material The online version of this article (doi:10.1007/s00109-009-0549-x) contains supplementary material, which is available to authorized users.

M. Ferrandi · I. Molinari • C. Camisasca • F. Palazzo • P. Ferrari Prassis sigma-tau Research Institute,

Settimo Milanese,

Milan, Italy

D. Cusi $\cdot$ C. Barlassina

Graduate School of Nephrology, University of Milan,

Milan, Italy

D. Cusi $\cdot$ C. Barlassina $\cdot$ F. Macciardi

Department of Medicine, Surgery and Dentistry,

AO San Paolo, University of Milan,

Milan, Italy

D. Cusi $\cdot$ C. Barlassina

Genomics and Bioinformatics Unit, Fondazione Filarete,

Milan, Italy

L. Del Vecchio

Department of Nephrology and Dialysis,

A. Manzoni Hospital,

Lecco, Italy

M. P. Rastaldi $\cdot$ S. Armelloni $\cdot$ L. Min $\cdot$ L. Giardino $•$

D. Mattinzoli

Laboratorio di Ricerca Nefrologica, Fondazione IRCCS Ospedale

Maggiore Policlinico \& Fondazione D’Amico per la Ricerca sulle

Malattie Renali,

Milan, Italy hypertension and renal dysfunction. Here, we have addressed the role of $\alpha$ - and $\beta$-adducin on glomerular function and disease using $\beta$-adducin null mice, congenic substrains for $\alpha$ - and $\beta$-adducin from the Milan hyperten-
F. P. Schena

Division of Nephrology, Department of Emergency and Organ

Transplantation, University of Bari,

Bari, Italy

C. Marcantoni

Division of Nephrology, University Hospital,

Verona, Italy

D. Roccatello

Department of Medicine and Experimental Oncology,

Clinical Pathology, University of Turin,

Turin, Italy

L. L. Peters

The Jackson Laboratory,

Bar Harbor, ME, USA

F. Macciardi

Department of Psychiatry and Human Behavior,

University of California, Irvine (UCI),

Irvine, CA, USA

P. Manunta $\cdot$ G. Bianchi $(\bowtie)$

Division of Nephrology and Dialysis, Chair of Nephrology,

San Raffaele Scientific Institute,

Università "Vita-Salute" San Raffaele Hospital,

Milan, Italy

e-mail: bianchi.giuseppe@hsr.it 
sive (MHS) and Milan normotensive (MNS) rats and patients with $\operatorname{IgA}$ nephropathy. Targeted deletion of $\beta$ adducin in mice reduced urinary protein excretion, preceded by an increase of podocyte protein expression (phosphonephrin, synaptopodin, $\alpha$-actinin, ZO-1, Fyn). The introgression of polymorphic MHS $\beta$-adducin locus into MNS $(A d d 2,529 \mathrm{R})$ rats was associated with an early reduction of podocyte protein expression (nephrin, synaptopodin, $\alpha$ actinin, ZO-1, podocin, Fyn), followed by severe glomerular and interstitial lesions and increased urinary protein excretion. These alterations were markedly attenuated when the polymorphic MHS $\alpha$-adducin locus was also present (Add1, 316Y). In patients with IgA nephropathy, the rate of decline of renal function over time was associated to polymorphic $\beta$-adducin (ADD2, 1797T, rs4984) with a significant interaction with $\alpha$-adducin (ADD1, 460W, rs4961). These findings suggest that adducin genetic variants participate in the development of glomerular lesions by modulating the expression of specific podocyte proteins.

Keywords Adducin · Genetic renal disease · Glomerular disease $\cdot \operatorname{Ig}$ A nephropathy $\cdot$ Podocytes $\cdot$ Proteinuria

\section{Introduction}

Renal failure, triggered by a variety of factors, is a major and costly health care burden. After an apparently similar initial glomerular injury, large individual variations occur in the rate of progression toward renal failure as well as in the magnitude of urinary protein excretion, which is the major predictor of disease progression [1]. Polymorphisms within genes encoding a few proteins associated with the podocyte actin cytoskeleton are responsible for glomerular proteinuria and progression toward failure in some monogenic and polygenic glomerular diseases [2-5].

Adducin is a heterodimeric protein composed by $\alpha, \beta$, and $\gamma$ subunits, encoded by distinct genes, that regulate actin polymerization and bundling as well as basic cellular functions involving the actin cytoskeleton, such as ion transport, cell motility, morphology, and adhesion [6, 7]. Genetic variations within adducin genes have been shown to be involved in primary hypertension in rats and humans [8-11].

To date, no link has been suggested between adducin polymorphisms and podocyte or glomerular function [2]. Indeed, $\alpha$ - and $\beta$-adducin polymorphisms have been variously found to be associated with progression of renal failure in the presence of overt nephropathy or with decay of renal function in population studies [12-16], although the results have not been consistent [17]. Polymorphisms within the $\alpha$ - and $\beta$-adducin genes occur in rodents $(\alpha$ - adducin, $A d d 1$, F316Y; $\beta$-adducin, $A d d 2$, Q529R) [7, 8, 10] and humans ( $\alpha$-adducin, ADD1, G460W, rs4961 and S586C, rs 4963; $\beta$-adducin, ADD2, C1797T, rs4984) [9, 10], although at different positions, therefore different outcomes might be expected between species as function of these genetic variants. These observations call for a set of experimental and clinical approaches aimed at establishing whether these genetic variations within the $\alpha$ - and $\beta$ adducin genes are associated with changes in glomerular or podocyte function both in rodents and humans. This aim was pursued with the following three approaches to evaluate the impact of adducin variations across different contexts and to test to what extent rodent data may help in understanding human data: (1) the effect of the knockout of the $\beta$-adducin gene in mice on blood pressure, urinary protein excretion, and podocyte protein expression; (2) the effect of the introgression of a DNA segment, harboring the polymorphic $\alpha$ - and $\beta$-adducin loci from the Milan hypertensive rat strain (MHS) into the normotensive strain (MNS; congenic rat substrains) on blood pressure, urinary protein excretion, glomerular morphology, and function and podocyte protein expression; and (3) the association of $\alpha$ and $\beta$-adducin genotypes with the rate of decline of renal function in patients with IgA nephropathy.

IgA nephropathy was selected as disease model for several reasons, among which: (1) it is the commonest glomerulonephritis worldwide, (2) its outcome is extremely variable, spanning from decades of normal renal function to fast progression toward end stage renal disease [18], and (3) few clinical features have been detected as predictors of progression rate [19].

\section{Materials and methods}

Animal models

All procedures for animal care were carried out in accordance with Prassis Institutional Guidelines. The care and husbandry of animals complied with the European Directives no 86/609 and with the Italian Law (DL116, January 27, 1992). The authorization for animal use in Prassis Laboratories was obtained from the Italian Health Authority. Animals had free access to the chow (standard diet, Altromin, Rieper, Italy) and to tap water and were maintained under controlled conditions of air temperature $\left(22 \pm 2^{\circ} \mathrm{C}\right)$, relative humidity $(50 \pm 15 \%)$, and day/night cycle $(12 \mathrm{~h})$ :

1. $\beta$-Adducin (Add2) null mouse model: $\beta$-adducin knockout mice (official strain designation 129Add $2^{\text {tm1Llp }} /$ Llp) have been previously described [20]. Wild-type $129 / \mathrm{Sv}$ mice, carrying the same $\beta$-adducin 
polymorphism (Q529R) described in the MHS rats [7], were used as controls.

2. Selection of congenic rat substrains from MHS and MNS parental strains: MHS, hypertensive, and MNS, normotensive, parental rats were derived from the internal stock colony (Prassis sigma-tau). Congenic rat strains were obtained from MHS hypertensive and MNS normotensive strains, as described [21]. The donor strain was the MHS and the receiving genetic background was the MNS. The integrated physical and linkage map of the congenic segment indicated that the reciprocal congenics for $\alpha$-adducin $(A d d 1)$ contained a minimum/maximum of $1.0 / 8.8 \mathrm{Mb}(6.6 \mathrm{cM})$ and that for $\beta$-adducin $(\operatorname{Add} 2)$ a minimum/maximum of $1.0 /$ $26.4 \mathrm{Mb}(13.5 \mathrm{cM})[21]$.

Systolic blood pressure (SBP) and heart rate were recorded in conscious rats (from 2 to 6 months of age) and in mice (at 8 and 11 months) by an indirect tail-cuff plethysmographic method (BP recorder, U. Basile, Varese, Italy).

Biochemical assays for urinary parameter measurements

Urinary parameters were measured in conscious male rats at $1.5,3,6,8$, and 11 months of age. Rats were housed in individual metabolic cages and had free access to water and food. Urinary parameters were also measured in conscious wild-type and knockout mice at 8 and 11 months of age. Mice received a bolus of $1 \mathrm{ml}$ physiological solution by gavages, and urine was collected over a period of $6 \mathrm{~h}$. Urine samples were analyzed for the following parameters: volume, $\mathrm{pH}$, osmolality, $\mathrm{Na}^{+}$and $\mathrm{K}^{+}$concentrations (IL 943 photometer), total protein excretion (total protein Kit, Sentinel Diagnostics, Milan, Italy), and creatinine (colorimetric Kit, Sentinel Diagnostics).

Histological and immunohistochemical studies

Renal tissue samples for light microscopy were fixed in $4 \%$ buffered paraformaldehyde and embedded in paraffin. Routine staining was performed on $2-\mu \mathrm{m}$-thick sections according to standard techniques [22].

For immunofluorescence and immunohistochemistry, unfixed renal tissue was embedded in OCT compound (Miles Scientific, Naperville, IL, USA), snap-frozen in a mixture of isopentane and dry-ice, and stored at $-80^{\circ} \mathrm{C}$. Five-micrometer sections were placed on slides and fixed in cold acetone. In indirect immunofluorescence, the bound primary antibody was detected by Alexa Fluor 488 antirabbit or antimouse IgG (Invitrogen). For immunohistochemistry, after blocking endogenous biotin and endogenous peroxidase, the primary antibody was followed by an appropriate biotinylated secondary antibody and peroxidase-labeled streptavidin (both from Invitrogen), finally developed by diaminobenzidine (Sigma). Slides were mounted either with Vecta-shield aqueous mounting medium (Vector Laboratories, DBA Italia SRL) or with Bio Mount (Bio Optica, Milan, Italy).

Glomeruli and podocyte isolation

Kidneys were taken from 7- to 10-day-old rats. Glomeruli were isolated by sieving then seeded in culture flasks precoated with collagen type IV (Sigma-Aldrich) at $37^{\circ} \mathrm{C}$ in $5 \% \mathrm{CO}_{2}$ atmosphere. On days 4 to 5 , podocyte growth started, and by day 8 , glomeruli were detached using trypsin-EDTA and filtered through the $36-\mu \mathrm{m}$ mesh to eliminate glomeruli. Second passage podocytes, $>90 \%$ pure as judged by light microscopy, were seeded on flasks and chamber slides. Cell characterization was performed by immunofluorescence, using markers for podocytes (nephrin, podocin), epithelial (cytokeratin), smooth muscle $(\alpha$ SMA), and endothelial cells (CD31).

\section{Western blotting}

Samples were separated by sodium dodecyl sulfatepolyacrylamide gel electrophoresis, blotted and overnight incubated at $4^{\circ} \mathrm{C}$ with specific primary antibodies, followed by $1 \mathrm{~h}$ incubation with fluorescent secondary antibodies (Alexa Fluor), then analyzed and quantified by Odyssey Infrared Imaging Detection System (LI-COR Biosciences). Antibodies were anti- $\alpha$ - and anti- $\beta$-adducin (raised by $S$. Salardi in Prassis); anti-nephrin, anti-Fyn (Santa Cruz); anti-phospho-nephrin (kindly provided by Larry Holzman); anti-vimentin, anti-ZO-1, anti- $\alpha$-SMA (Invitrogen); anti-synaptopodin (Progen Biotechnik); anti- $\alpha$-actinin (Calbiochem); anti-podocin, anti-actin (Sigma-Aldrich); and anti-cytokeratin, anti-CD31 (Abcam).

Human studies

Informed consent was obtained from all participants in the study, which was approved by the Ethical Committee of the San Raffaele Hospital, Milan, Italy.

Three hundred seventy-three patients, with biopsy proven primary IgA nephropathy (IgAN), were included in the study. Enrolling patients began in 1994 with the intent to recruit both incident cases and cases that were already being followed up. Only Caucasian patients of Italian origin were selected. The only selection criteria were willingness of the patient to participate and a follow-up longer or equal to 4 years. Clinical and anthropometric parameters, blood pressure values, and laboratory data at the time of renal biopsy were collected. After renal biopsy, 
all patients were followed up regularly with laboratory analyses and clinical evaluations (at least once per year) at their respective centers. Urinary protein excretion varies considerably from day to day, but average values remain fairly constant in IgAN, at least within the first 3 years after diagnosis [23]; the average of the urinary protein excretion over the first 2 years after biopsy was therefore used for analysis. Glomerular filtration rate (GFR) was computed with the Cockcroft-Gault formula [24]. The individual rate of renal function decline was computed separately for each patient with the least squares method and expressed the loss of GFR per year $\left(\mathrm{ml} \mathrm{min}^{-1}\right.$ year $\left.^{-1}\right)$. Twenty-eight subjects were excluded because their data set was incomplete or their DNA failed to amplify and 17 because they showed a biphasic course of their GFR over time. Their renal function remained almost normal (serum creatinine less than $1.5 \mathrm{mg} / \mathrm{dl}$ ) and stable for a variable number of years, before dropping abruptly with fast progression to end stage renal disease. We and others [25] considered these cases as atypical.

The minimum number of GFR determinations used to compute progression rate was four per patient, while the average number of GFR values analyzed was $9.28 \pm 0.28$ (8.74-9.83, 95\% confidence interval) per patient. Severity of renal damage according to Lee et al. [26] was scored by two experienced pathologists, blind for patient's clinical features, outcome, and adducin genotype, with an interrater reproducibility higher than $90 \%$. The grading system of Lee et al. consists of a single score (grades I to V) and summarizes glomerular and, to a lesser degree, interstitial lesions. Higher grades include crescent formation and interstitial fibrosis.

\section{Genotyping for $\alpha$ - and $\beta$-adducin}

Genotyping was carried out on an ABI PRISM 7700 Sequence Detection System using the $5^{\prime}$ nuclease detection assay, as described [27].

\section{Statistical analysis}

Statistical analysis was performed with SPSS 16.0 (SPSS Inc., Chicago, IL, USA) and STATA 8 (Stata Corporation, College Station, TX, USA). Quantitative data were analyzed with Student's $t$ test, one-way analysis of variance (ANOVA), or by simple or multiple linear regression when appropriate. A $p$ value $<0.05$ (two-tailed) was considered significant. For human studies, progression rate was defined as the GFR decay each year $\left(\mathrm{ml} \mathrm{min}^{-1}\right.$ year $\left.^{-1}\right)$ in each individual subject. First simple linear regression models were tested with renal function loss as the dependent variable and, separately one for each model, urinary protein excretion, serum creatinine, serum IgA, body mass index (BMI), and hypertension at diagnosis, gender, age of onset, and severity grading of Lee et al. as independent variables. Then, the same variables were all entered in a multiple regression model in a stepwise procedure.

Test of genetic effects and interaction was performed with two-locus model fitting, and hypothesis testing was conducted via least squares regression analysis [28]. The fit of the different genetic models (additive versus dominant) was compared and evaluated based on the respective $F$ values of each model, and the one yielding the greatest $F$ test was assumed to be the most appropriate. The effects of the various nongenetic factors considered above (urinary protein excretion, serum creatinine, serum IgA, BMI, hypertension at diagnosis, gender, age of onset, severity grading of Lee et al.) were tested using multivariate analysis, by including them as main effects as well as interaction with genotypes. The nonsignificant effects (all of the above, except urinary protein excretion) were discarded from the model in a stepwise procedure.

As most of the patients were recruited before generalized use of angiotensin-converting enzyme (ACE) inhibition, only about $47 \%$ of the subjects received an antihypertensive therapy, either ACE inhibitors (ACEI; 37\%) or other drugs. This may affect the level of proteinuria. For this reason and for the fact that ACE inhibitor treatment was evenly distributed according to $\operatorname{ADD} 1\left(\chi_{1}^{2}=0.53 ; p=0.46\right)$ and $\operatorname{ADD} 2\left(\chi_{1}^{2}=0.80 ; p=0.37\right)$ genotype, ACE inhibition was not accounted for in the multivariate analysis but analyzed separately.

The authors had full access to the data and take responsibility for its integrity. All authors have read and agreed to the manuscript as written.

\section{Results}

Localization of $\alpha$-and $\beta$-adducin in the kidney

Immunostainings performed with specific anti-adducin antibodies in mice, rats, and humans revealed the presence of $\alpha$ - and $\beta$-adducin in renal glomeruli. Figure 1 shows a typical immunofluorescence analysis of rat glomeruli. Immunogold electron microscopy (supplementary data, Fig. S1) in rat kidneys indicated that both proteins were ubiquitously present in glomerular cells. In particular, $\alpha$ and $\beta$-adducins were present in podocytes. Reverse transcriptase polymerase chain reaction, immunogold, and Western blot analysis carried out in mouse, rat, and human podocytes confirmed the presence of mRNA and protein for $\alpha$ - and $\beta$-adducin isoforms (not shown).

\section{$\beta$-Adducin null mice}

Systolic blood pressure SBP did not differ between male and female $\beta$-adducin knockout mice and age- and sex- 
Fig. 1 Immunofluorescence analysis for $\alpha$ - and $\beta$-adducin localization in renal tissues. Immunostaining was performed on mouse, rat, and human renal sections by using specific antiadducin antibodies and indicated the presence of $\alpha$ - and $\beta$ adducin in glomerular cells. The figure shows a typical indirect immunofluorescence $(\times 400$ magnification) of rat glomeruli
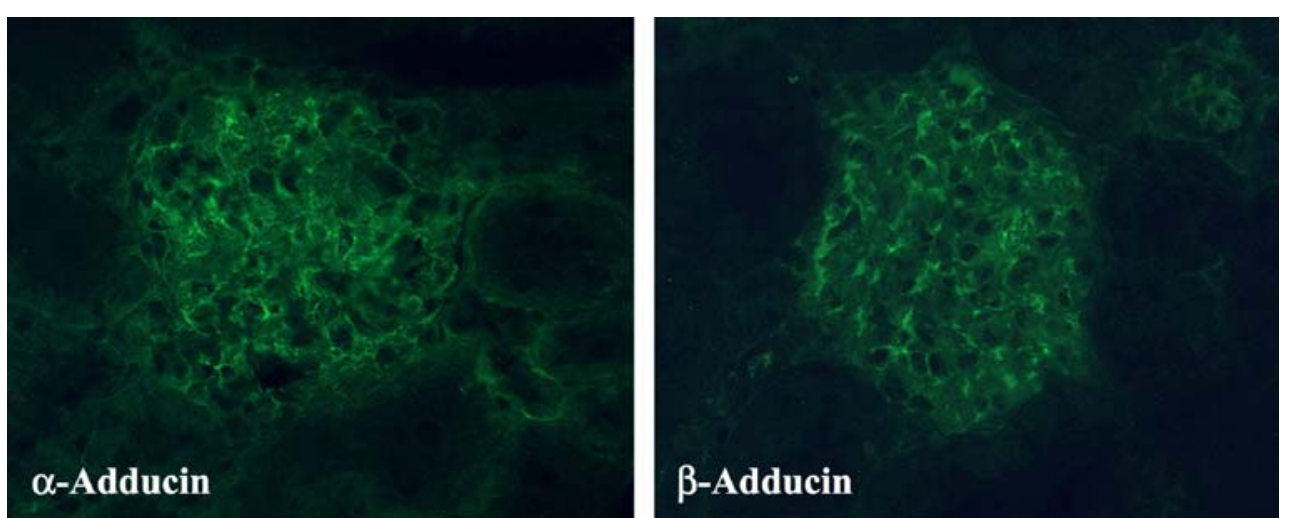

matched wild-type mice at 8 and 11 months of age. Figure 2 shows SBP in 11-month-old mice.

Renal studies No difference in urinary volume or $\mathrm{Na}^{+}, \mathrm{K}^{+}$, and creatinine excretion was detected between male and female knockout mice and wild-type controls at 8 and 11 months of age (not shown). However, compared to controls, male and female knockout mice showed a significant reduction of urinary protein excretion normalized for urinary creatinine excretion at both ages. Figure 2 shows proteinuria/creatinine ratio in 11-month-old mice. Immunostaining of proteins belonging to podocyte slit diaphragm (such as nephrin and Fyn) and foot process cytoskeleton (such as synaptopodin, $\alpha$-actinin, and ZO-1), performed in kidney sections from male 1.5-month-old wild-type and knockout mice, showed no $\beta$-adducin in knockout mice, a similar staining for $\alpha$-adducin and nephrin but an increased staining for synaptopodin, $\alpha$-actinin, ZO-1, and Fyn in knockout mice (Fig. 3; supplementary Fig. S2).

A Western blot analysis, performed on isolated glomeruli of 1.5-month-old mice, showed no $\beta$-adducin in knockout mice and a similar content of $\alpha$-adducin between the two groups (Fig. 4). Total nephrin was not different while phosphorylated nephrin was significantly increased in knockout mice, together with synaptopodin, $\alpha$-actinin, ZO-1, and Fyn. Podocin and actin were similar between the two groups (Fig. 4). The normalization of protein contents against actin did not change the pattern of differences between the two groups of mice. The supplementary Fig. S3 shows the Western blots of the individual
Fig. 2 Effect of $\beta$-adducin knockout on systolic blood pressure and proteinuria/creatinine ratio in mice. Indirect systolic blood pressure (upper) and urinary protein excretion normalized for urinary creatinine (lower) were measured in male and female wild-type $(W T)$ and knockout $(K O)$ mice at 8 and 11 months of age. Similar results have been obtained at the two ages. The figure shows the results at 11 months. Data are mean \pm SEM. Mouse numbers are indicated in the bars. ${ }^{*} p<<$ $0.01 \mathrm{KO}$ vs. WT

\section{Systolic Blood Pressure}

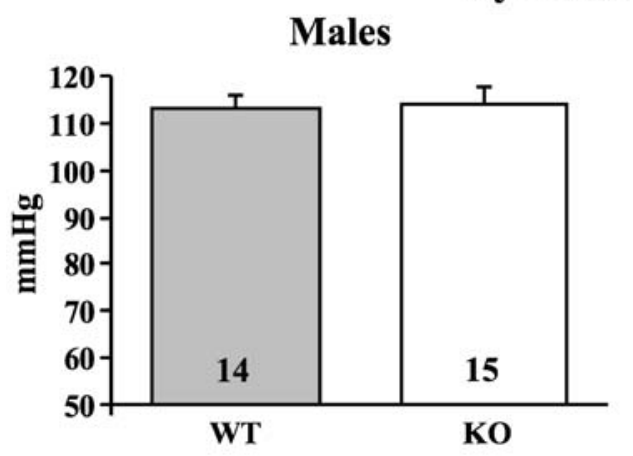

Females

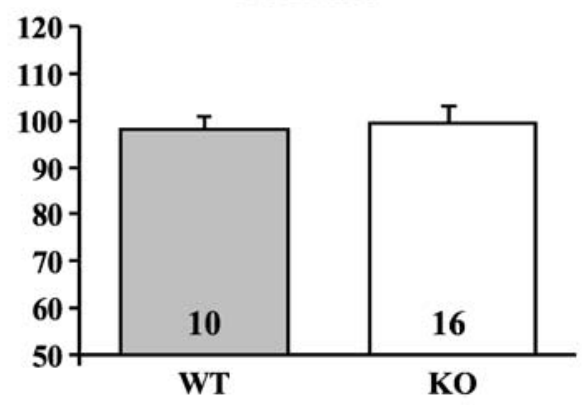

Proteinuria/Creatinine

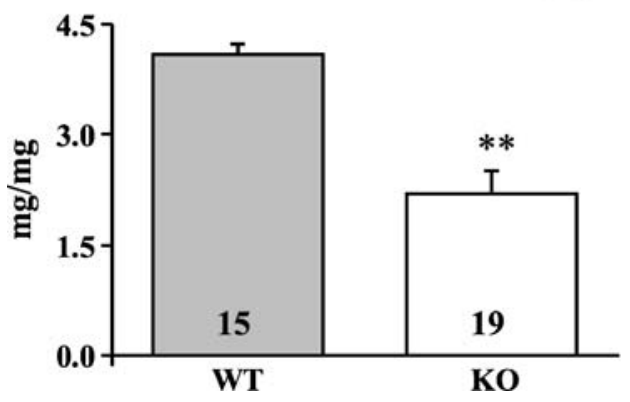

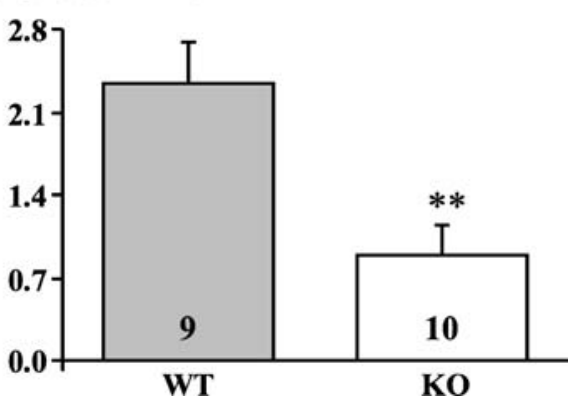


Wild - type mice
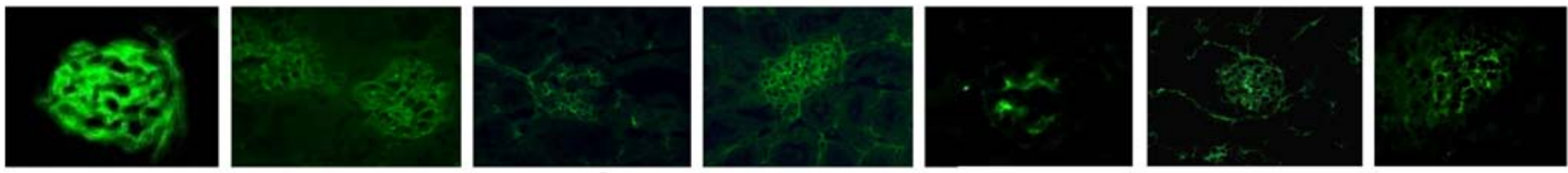
$\beta$-Adducin null mice
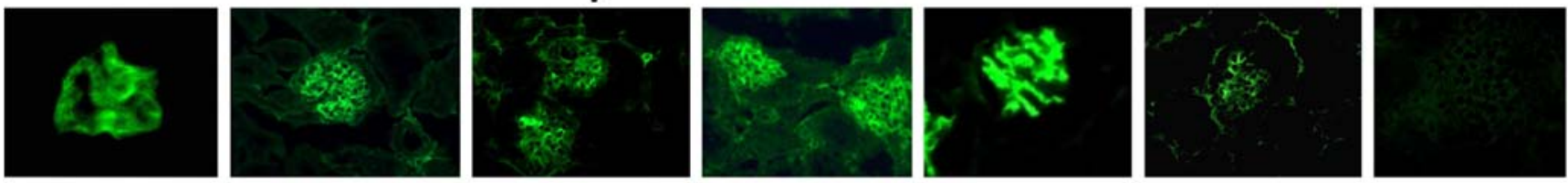

Nephrin

Synaptopodin

$\alpha$-Actinin

ZO-1

Fyn

$\alpha$-Adducin

$\beta$-Adducin

Fig. 3 Immunofluorescence analysis of podocyte proteins and $\alpha$ - and $\beta$-adducin in mouse kidney sections. Immunohistochemical expression of podocyte proteins from slit diaphragm (nephrin, Fyn) and foot process cytoskeleton (synaptopodin, $\alpha$-actinin, ZO-1) and $\alpha$ - and $\beta$ adducin was evaluated in kidney preparations from 1.5-month-old

renal glomerular preparation from wild-type $(n=5)$ and $\beta$ adducin knockout mice $(n=5)$, probed with the specific antibodies. These data suggest that the reduced proteinuria observed in $\beta$-adducin knockout mice, as compared to wild-type controls, is preceded by an increased expression of specific podocyte marker proteins.

\section{Western blot Densitometric analysis}

\begin{tabular}{|c|c|c|c|}
\hline & WT KO & WT $(n=5)$ & KO $(n=5)$ \\
\hline Nephrin & 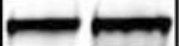 & $103.2 \pm 9.4$ & $132.8 \pm 19.9$ \\
\hline P-Nephrin & $m$ & $0.28 \pm 0.048$ & $0.45 \pm 0.04,{ }^{*} p<0.05$ \\
\hline Synaptopodin & 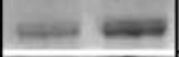 & $7.6 \pm 0.7$ & $17.3 \pm 0.5,{ }^{*} p<0.05$ \\
\hline$\alpha$-Actinin & $y=$ & $1.43 \pm 0.068$ & $3.31 \pm 0.64,{ }^{*} p<0.05$ \\
\hline ZO-1 & $=2$ & $2.13 \pm 0.19$ & $5.76 \pm 1.4,{ }^{*} p<0.05$ \\
\hline Fyn & $-\infty$ & $8.8 \pm 1.14$ & $12.8 \pm 0.69,{ }^{*} \mathrm{p}<0.05$ \\
\hline Podocin & $\lim _{0}$ & $10.2 \pm 0.75$ & $9.13 \pm 0.99$ \\
\hline B-Adducin & $\longrightarrow$ & $4.44 \pm 0.43$ & absent \\
\hline$\alpha$-Adducin & $-\cdots$ & $156 \pm 4.5$ & $189 \pm 26$ \\
\hline Actin & & $124.8 \pm 8.9$ & $140.5 \pm 10.1$ \\
\hline
\end{tabular}

Fig. 4 Western blot analysis of podocyte proteins in isolated glomeruli from $\beta$-adducin knockout mice. Renal glomeruli were isolated from 1.5-month-old male wild-type and $\beta$-adducin knockout mice. Five mice for each group were analyzed by Western blotting (10 $\mu \mathrm{g}$ protein/lane) using specific antibodies as indicated. The densitometric analysis is reported. The optical densities are expressed as arbitrary units. Data are mean \pm SEM. ${ }^{*} p<0.05 \mathrm{KO}$ vs. WT. Figure S3 in supplementary data shows the Western blots of the individual renal glomerular preparations from wild-type and $\beta$-adducin knockout mice male wild-type and $\beta$-adducin knockout mice. Five mice for each group were investigated. Magnification: nephrin $\times 1,000$; synaptopodin $\times 630$; $\alpha$-actinin WT $\times 630 ; \alpha$-actinin KO $\times 400 ;$ ZO- $1 \times 400 ;$ Fyn $\times 1,000 ; \alpha$ and $\beta$-adducin $\times 400$. Figure S2 in supplementary data shows the quantitative immunofluorescence analysis

Congenic rat substrains for $\alpha$ - and $\beta$-adducin

Systolic blood pressure As published [21], the introgression of $\alpha$-adducin from MHS into the MNS genetic background (NA congenic), but not that of $\beta$-adducin (NB congenic), significantly raises SBP in NA over MNS. Here, we have additionally demonstrated that in double-congenic strains (NAB), where polymorphic $\alpha$ - and $\beta$-adducin genes were simultaneously transferred from MHS into MNS rats, SBP did not differ from that of MNS at any age. Figure 5 shows SBP at 3 months. These data suggest that, although $\beta$ adducin, per se, seems not to affect SBP, it blunts the hypertensive effect of $\alpha$-adducin.

Renal studies MNS rats develop an age-dependent glomerulosclerosis and proteinuria [29-31] sustained by an increased glomerular production of thromboxane [31], while MHS are protected from a glomerular damage. To assess the involvement of $\alpha$ - and $\beta$-adducin gene polymorphisms on the progression of renal alterations, urinary parameters were measured in rat strains at different ages $(1.5,3,6,8$, 11 months). No urinary parameter (including $24 \mathrm{~h}$ urinary $\mathrm{Na}^{+}, \mathrm{K}^{+}$, creatinine, and proteinuria) differed among the various strains at 1.5 and 3 months of age (not shown). Protein excretion greatly increased with age in MNS and even more severely in $\mathrm{NB}$, while it remained low over time in MHS, NA, and NAB. Figure 5 shows proteinuria normalized for urinary creatinine excretion at 6 months of age. The values of proteinuria in rats are higher than in mice because of the presence of glomerulosclerosis in MNS rats [29-31].

Histological studies, carried out in kidney preparations of rat strains at 3 months of age, showed normal glomeruli and normal interstitium (not shown), whereas at 6 and 


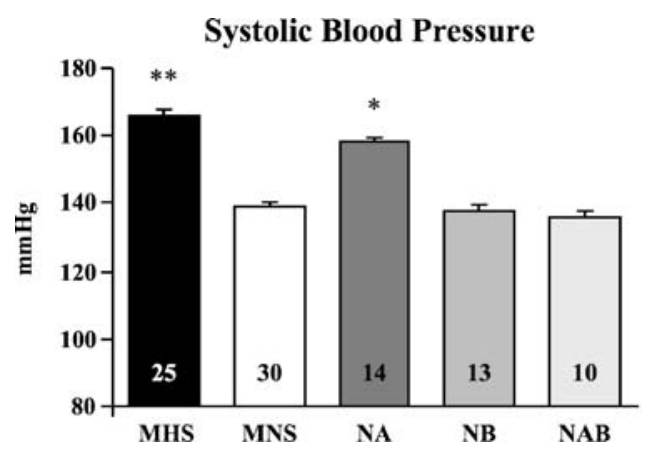

Fig. 5 Systolic blood pressure and proteinuria/creatinine ratio in congenic rat substrains for $\alpha$ - and $\beta$-adducin. Indirect systolic blood pressure (left) and urinary protein excretion normalized for creatinine excretion (right) were measured in male parental hypertensive MHS and normotensive MNS rats and in congenic substrains obtained by introgressing $\alpha$-adducin $(N A), \beta$-adducin $(N B)$, and $\alpha \beta$-adducin

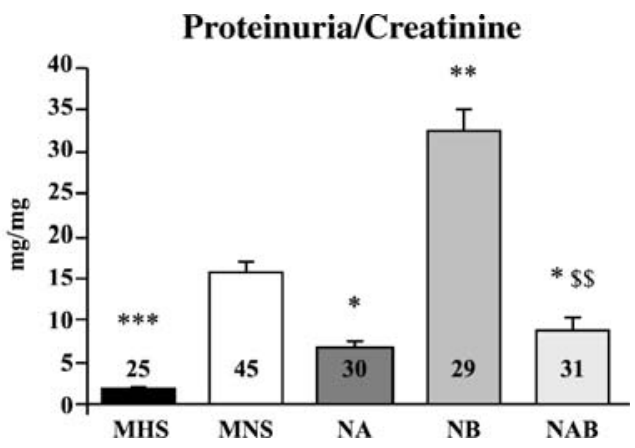

$(N A B)$ from MHS into the MNS genetic background. The measurements have been done in rats at 3 (left) and 6 (right) months of age. Data are mean \pm SEM. Rat numbers are indicated in the bars. No variation of heart rate was observed in any congenic substrain as compared to MNS (not shown). ${ }^{*} p<0.05,{ }^{*} p<0.01, * * * p<0.001$ vs. MNS; $\$ \$ p<0.01$ vs. NB
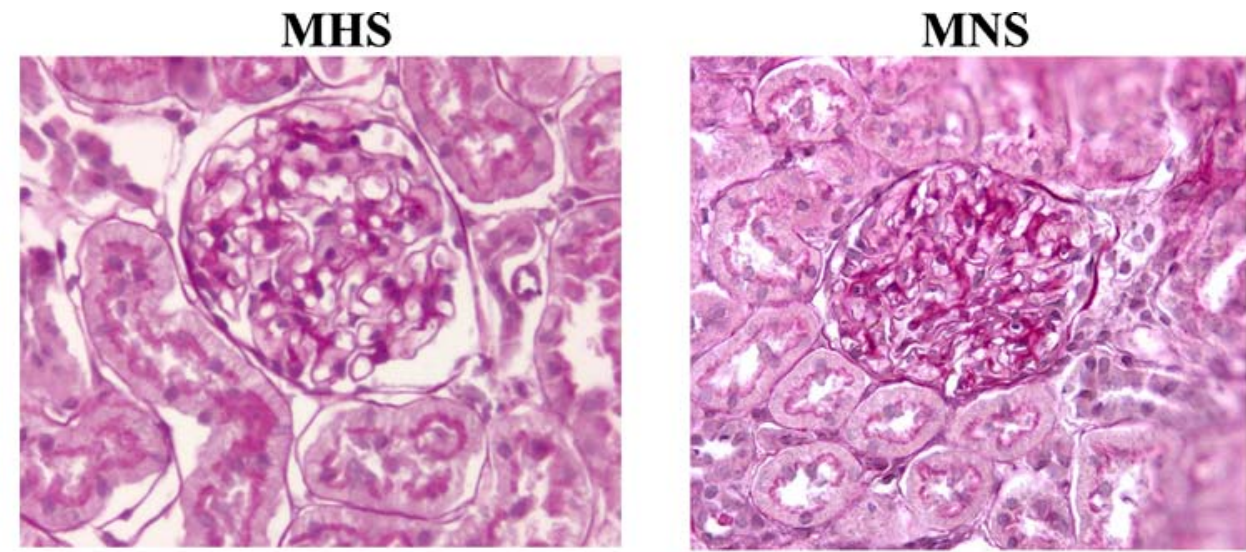

NA

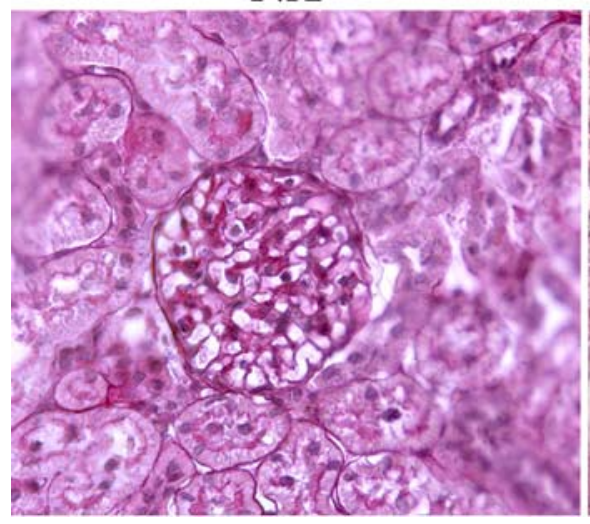

Fig. 6 Glomerular morphologic analysis in kidneys from congenic rat substrains for $\alpha$ - and $\beta$-adducin. Histomorphological studies have been conducted in kidney preparations from male parental hypertensive MHS and normotensive MNS rats and in congenic substrains for $\alpha$-adducin $(N A), \beta$-adducin $(N B)$, and $\alpha \beta$-adducin $(N A B)$. The analysis has been performed in rats at 6 months of age. The increased urinary protein excretion of MNS, which was even higher in NB,
NB

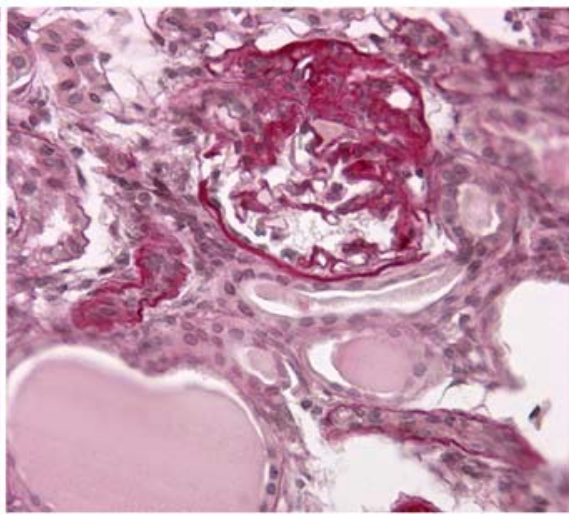

NAB

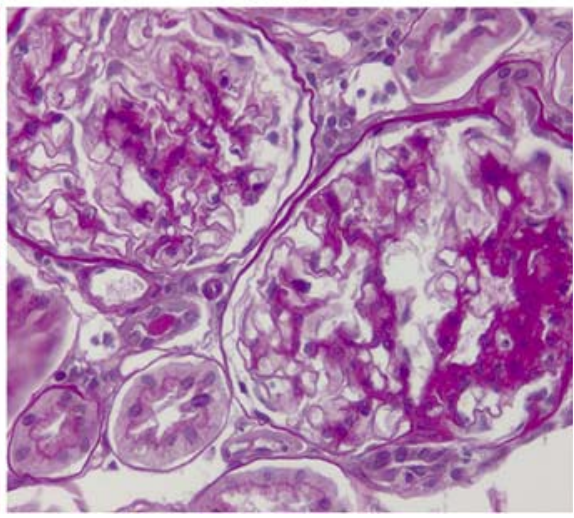

paralleled the appearance of glomerular and interstitial alterations as described in the text. The presence of MHS $\alpha$-adducin in MHS, NA, and NAB appeared to protect against proteinuria and glomerular damage. Five rats for each group were analyzed. Magnification: MHS and NAB $\times 400$; MNS, NA, and NB $\times 250$. Figure $S 4$ in supplementary data shows the quantitative morphometric analysis 
11 months of age, glomerular and interstitial damage paralleled the increase of proteinuria in MNS as compared to MHS (Fig. 6). In NB, where a massive proteinuria was observed (Fig. 5), histological alterations (mesangial proliferation, mesangial matrix expansion, segmental glomerulosclerosis, interstitial leukocyte infiltration, focal areas of interstitial fibrosis, tubular dilation and giant tubular protein casts), were even more severe than in MNS rats (Fig. 6). Conversely, no histological alteration was observed in MHS, NA, and NAB strains, where MHS $\alpha$-adducin was present (Fig. 6). The supplementary Fig. S4 shows the quantitative morphometric analysis of histological data obtained from five rats per group. Electron microscopy, carried out in 3-month-old rats, confirmed the presence of podocyte foot process effacement in MNS and NB, while NA appeared protected (supplementary Fig. S5).

The immunohistochemical expression of podocyte proteins, evaluated in kidney preparations from 1.5-month-old rats, where no difference in proteinuria was present among all strains, showed a decreased expression of nephrin, synaptopodin, $\alpha$-actinin (Fig. 7), ZO-1, Fyn (Fig. 8), Pcadherin (not shown), and $\alpha$-adducin (Fig. 9) in MNS and NB strains as compared to MHS, NA, and NAB.
Conversely, $\beta$-adducin (Fig. 9) and vimentin (Fig. 8), a microfilament localized in the podocyte cell body, were normally expressed in all strains. The supplementary Figs. S6 and S7 show the quantitative analysis of these data obtained from five rats per group. Note that $\alpha$-adducin, but not $\beta$-adducin, was less expressed in MNS and NB (Fig. S7).

A Western blot analysis of isolated glomeruli from 25- to 45-day-old rats showed a similar content of actin but a reduced expression of nephrin, either normalized or not against actin, in MNS and NB as compared to MHS, NA, and NAB rats (Fig. 10). The supplementary Fig. S8 shows the Western blots for nephrin and actin of the individual renal glomerular preparations from rat substrains. Five rats per group were analyzed.

Furthermore, a Western blot analysis of some podocyte markers, performed on primary cultures of glomerular podocytes from 10-day-old rats, confirmed a decreased expression of nephrin, $\alpha$-actinin, ZO-1, podocin, and $\alpha$ adducin in MNS and NB compared to NA podocytes (Fig. 11). Conversely, $\beta$-adducin (supplementary Fig. S9) and actin expression (Fig. 11) was similar among the three groups. The normalization of protein contents against actin

\section{Nephrin}
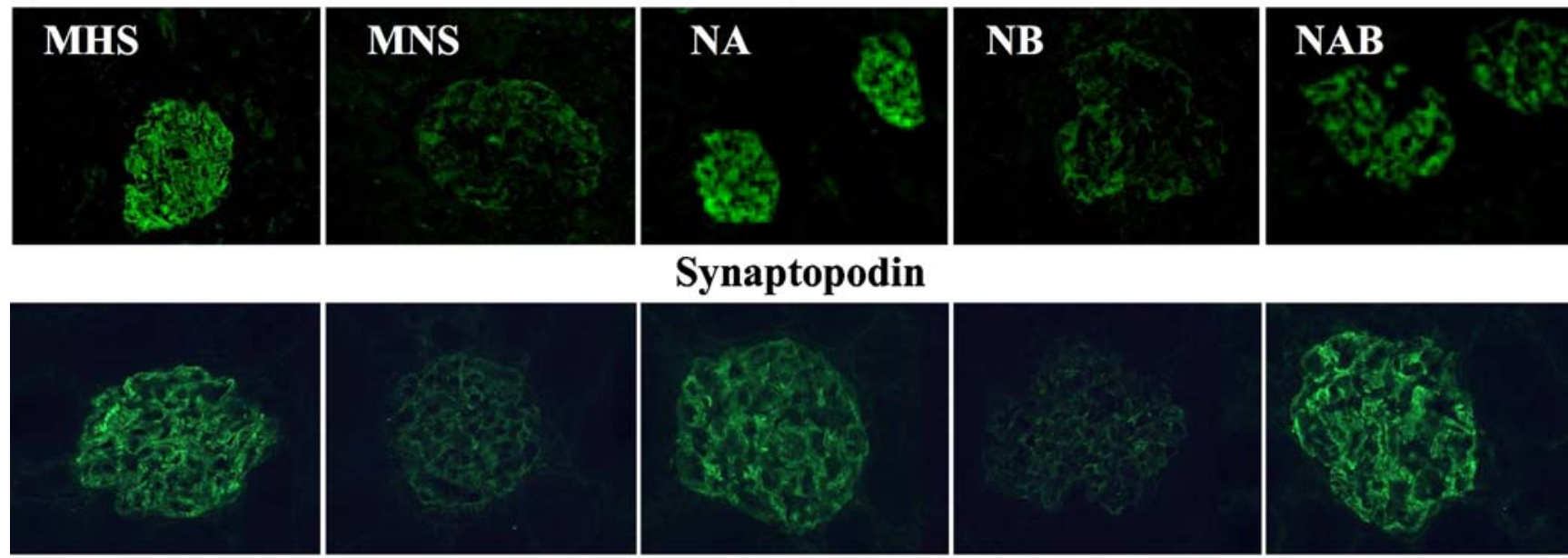

\section{Synaptopodin}
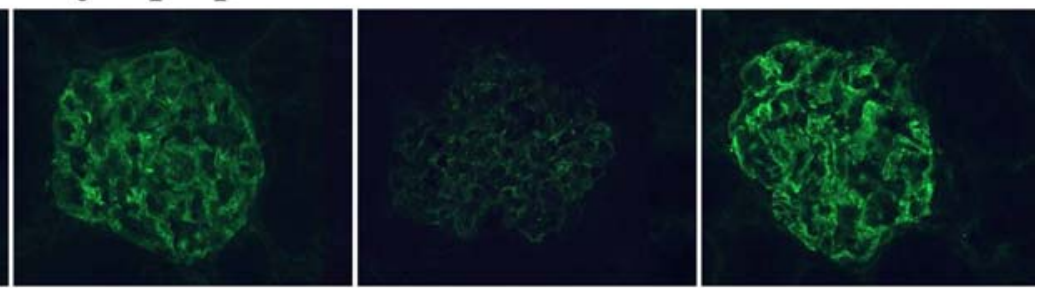

\section{$\alpha$-Actinin}
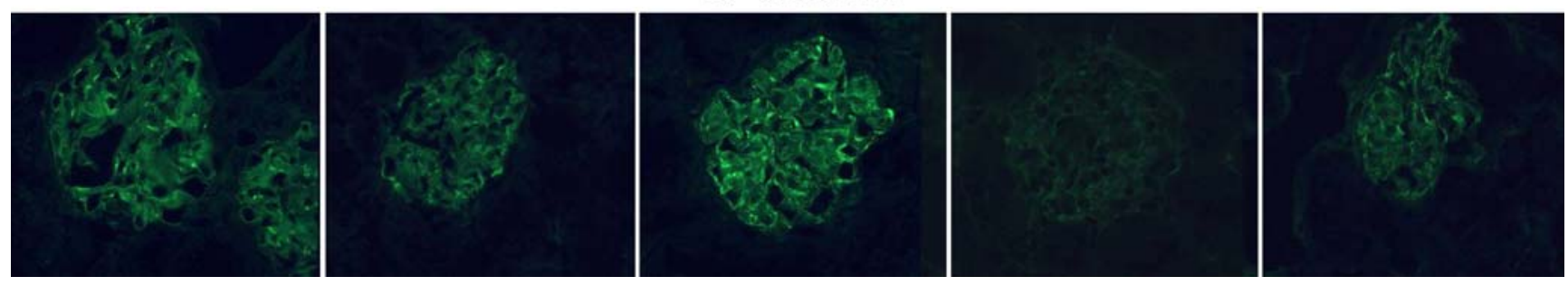

Fig. 7 Immunofluorescence analysis of podocyte proteins in kidney sections from congenic rat substrains for $\alpha$ - and $\beta$-adducin. Immunohistochemical expression of podocyte proteins (nephrin, synaptopodin, $\alpha$-actinin) was evaluated in kidney preparations from 1.5 -month-old male MHS, MNS rats and in congenic substrains for $\alpha$ - adducin $(N A), \beta$-adducin $(N B)$, and $\alpha \beta$-adducin $(N A B)$. Five rats for each group were analyzed. Magnification: nephrin MHS and NA $\times 250$; nephrin MNS, NB, and NAB $\times 400$; synaptopodin and $\alpha$-actinin $\times 400$. Figure S6 in supplementary data shows the quantitative immunofluorescence analysis 

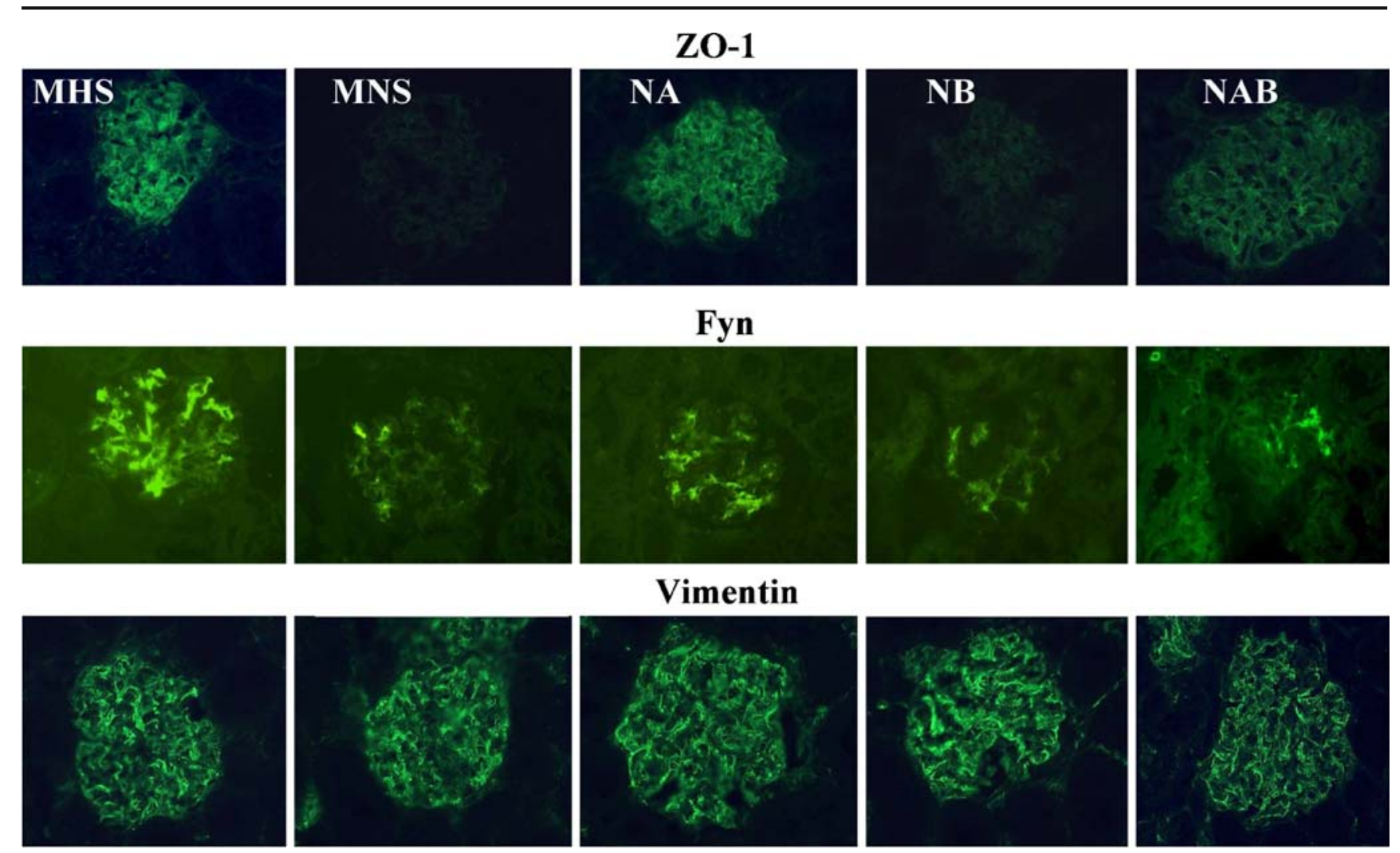

\section{Fyn}
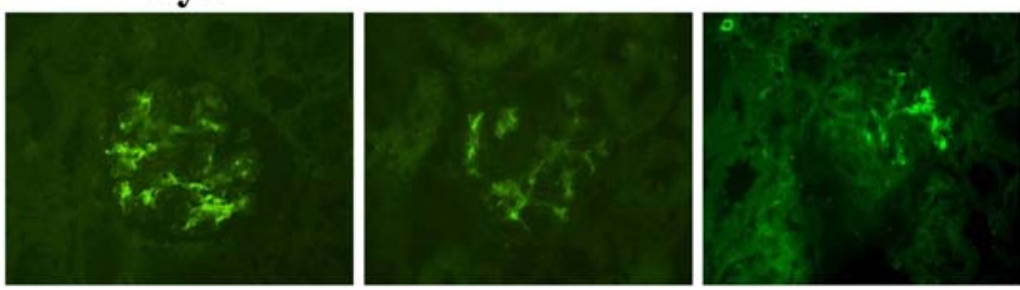

\section{Vimentin}
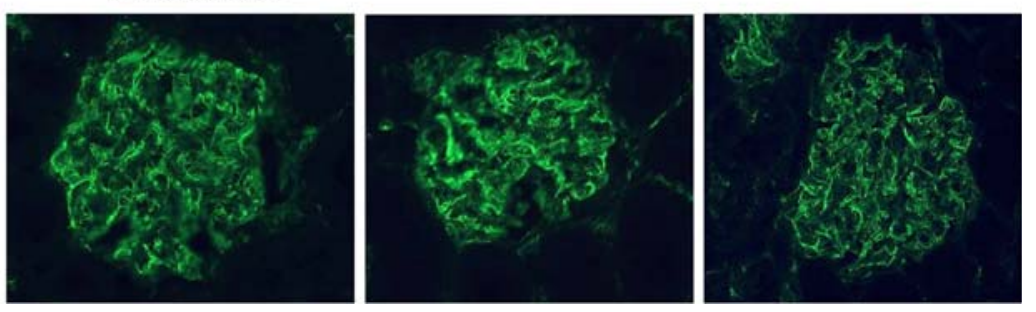

Fig. 8 Immunofluorescence analysis of podocyte proteins in kidney sections from congenic rat substrains for $\alpha$ - and $\beta$-adducin. Immunohistochemical expression of podocyte proteins (ZO-1, Fyn, vimentin) was evaluated in kidney preparations from 1.5-month-old male MHS,

did not change the pattern of differences among the three groups of rats. The supplementary Fig. S9 shows the Western blots of the individual glomerular podocyte preparations from congenic rats.
MNS rats and in congenic substrains for $\alpha$-adducin $(N A), \beta$-adducin $(N B)$, and $\alpha \beta$-adducin $(N A B)$. Five rats for each group were analyzed. Magnification: ZO-1, Fyn, vimentin $\times 400$. Figure S6 in supplementary data shows the quantitative immunofluorescence analysis

The present findings suggest that the pronounced proteinuria in MNS and NB strains, carrying the $\beta$ adducin genetic variant, is preceded by an early alteration of podocyte protein expression responsible for the changes

\section{$\alpha$-Adducin}
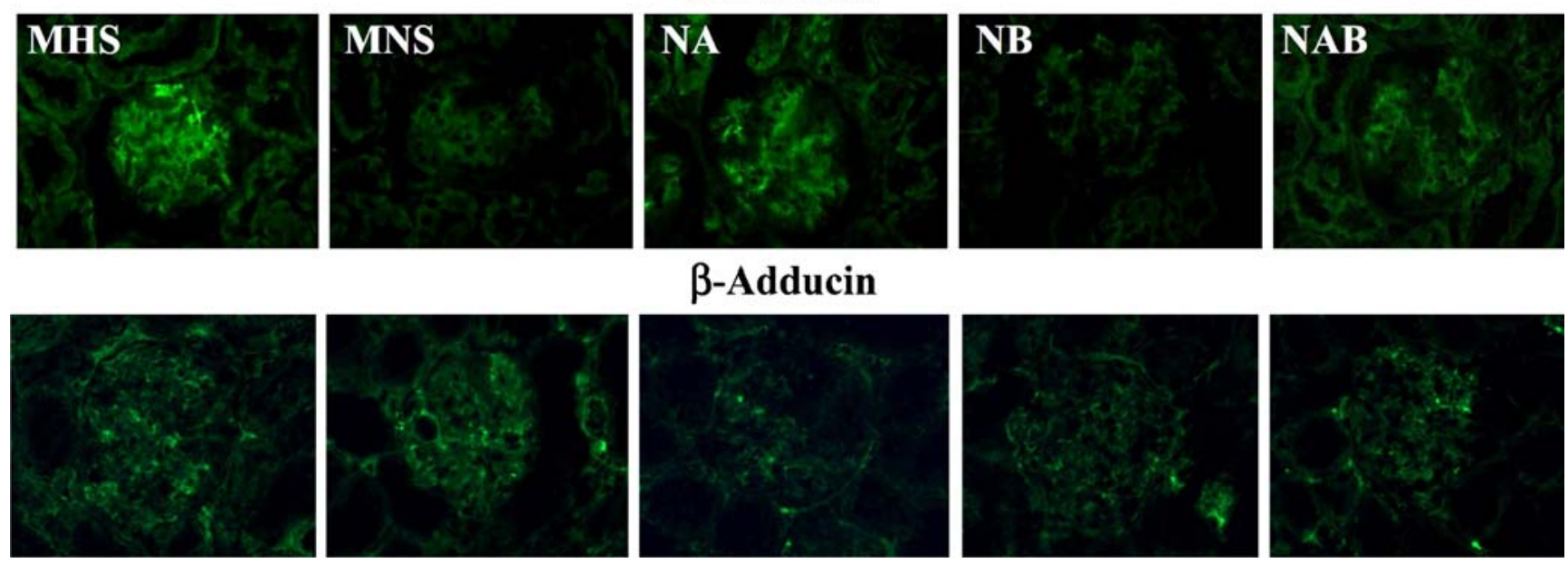

\section{$\beta$-Adducin}
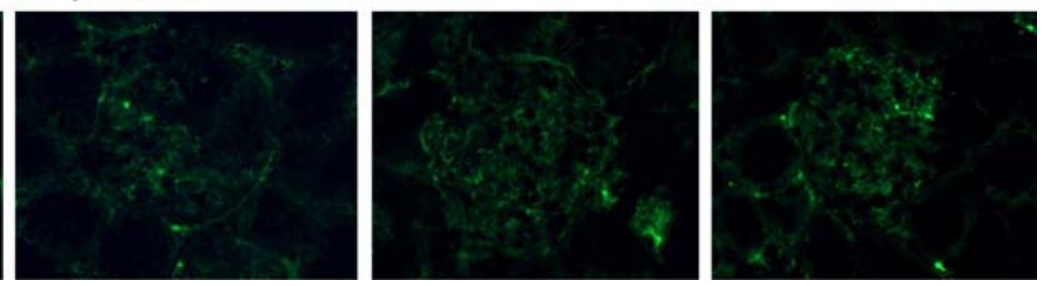

Fig. 9 Immunofluorescence analysis of $\alpha$ - and $\beta$-adducin in kidney sections from congenic rat substrains. Immunohistochemical expression of $\alpha$-and $\beta$-adducin was evaluated in kidney preparations from 1.5 -month-old male MHS, MNS rats and in congenic substrains for $\alpha$ -

adducin $(N A), \beta$-adducin $(N B)$, and $\alpha \beta$-adducin $(N A B)$. Five rats for each group were analyzed $(\times 400$ magnification). Figure S7 in supplementary data shows the quantitative immunofluorescence analysis 
Nephrin

$185 \mathrm{kDa}-$
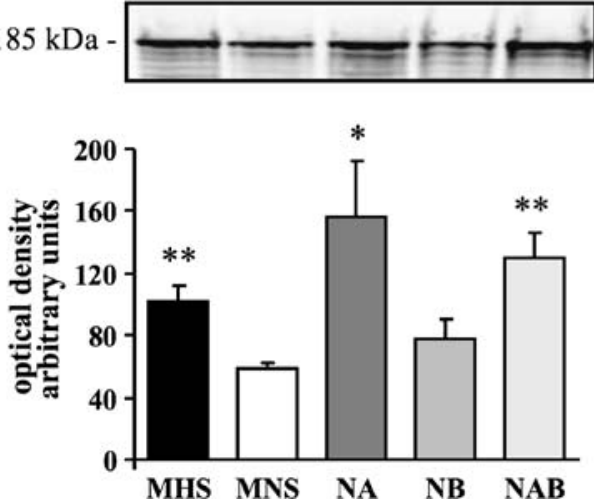

Actin

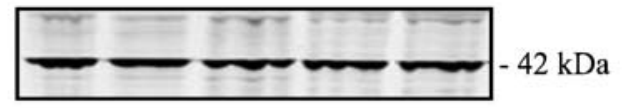

Nephrin / Actin

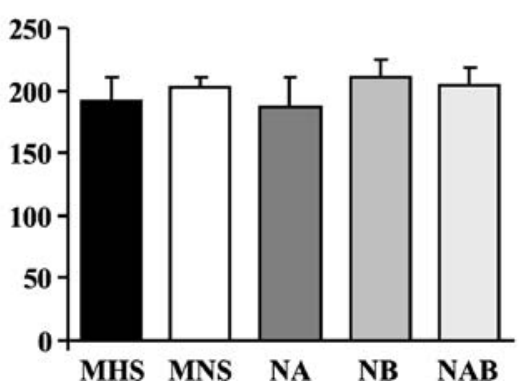

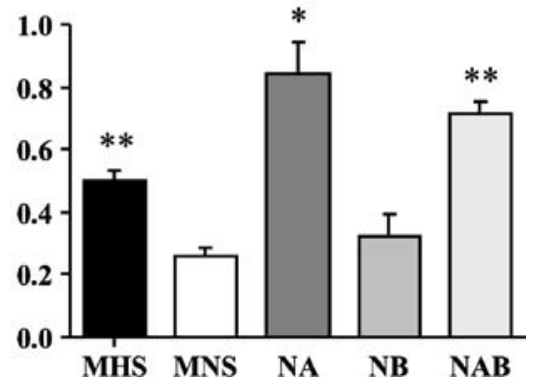

Fig. 10 Western blot analysis of nephrin and actin in isolated glomeruli from congenic rat substrains for $\alpha$ - and $\beta$-adducin. Renal glomeruli were isolated from 25-45-day-old male MHS, MNS rats and congenic substrains for $\alpha$-adducin $(N A), \beta$-adducin $(N B)$, and $\alpha \beta$ adducin $(N A B)$. Five rats for each group were analyzed by Western blotting (10 $\mu \mathrm{g}$ protein/lane) using specific antibodies against nephrin and actin. The densitometric analysis is reported as arbitrary units. Data are mean \pm SEM. ${ }^{*} p<0.05,{ }^{* *} p<0.01$ vs. MNS. Figure S8 in supplementary data shows the Western blots for nephrin and actin of the individual renal glomerular preparations from rat substrains of the glomerular filtration barrier permeability associated with protein leakage. Conversely, the MHS $\alpha$-adducin variant seems to be protective in MHS, NA, and NAB rats.
Renal function loss in patients with $\operatorname{IgA}$ nephropathy

Baseline data of the total sample are reported in Table 1. At univariate analysis, urinary protein excretion $\left(R^{2}=0.214\right.$,
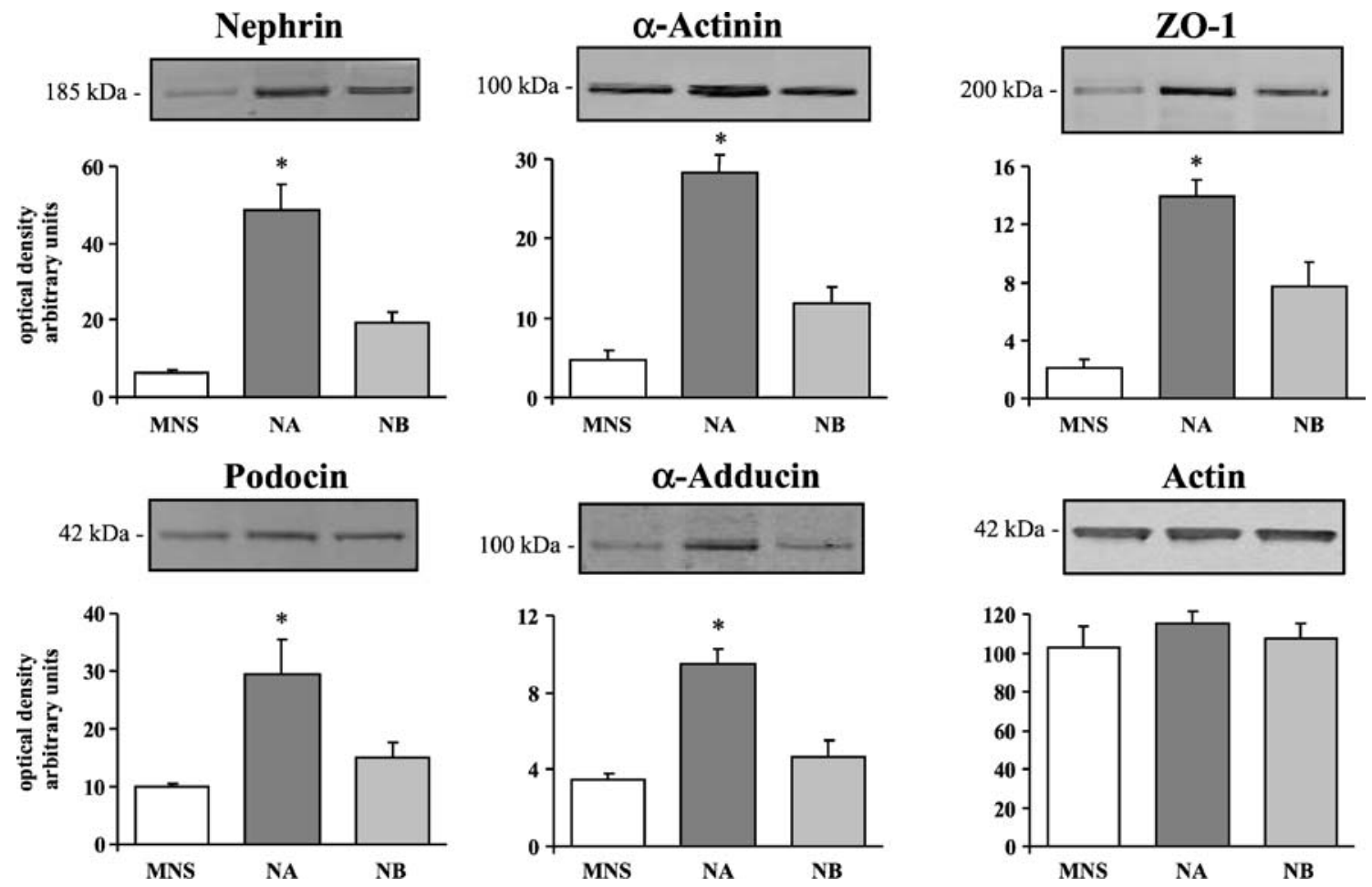

Fig. 11 Glomerular podocyte cultures from MNS rats and congenic substrains for $\alpha$-adducin $(N A)$ and $\beta$-adducin $(N B)$. Neonatal rats ( $<10$ days old) were used for podocyte culture preparations that were analyzed by Western blotting (10 $\mu \mathrm{g}$ protein/lane) using specific antibodies as indicated. Four preparations from MNS and NA and seven from NB rats were analyzed. The densitometric analysis is reported. The optical densities are expressed as arbitrary units. Data are mean \pm SEM. ${ }^{*} p<0.05$ vs. MNS. Figure S9 in supplementary data shows the Western blots of the individual glomerular podocyte preparations from rat substrains 
Table 1 Baseline patient demographics, clinical and laboratory data

\begin{tabular}{ll}
\hline Variable & Mean (range) \pm SEM \\
\hline Age at presentation (years) & $31.51(16-77) \pm 0.77$ \\
Age at biopsy (years) & $34.73(16-77) \pm 0.79$ \\
Males (\% men) & $247(75.3 \%)$ \\
Hypertensive (\%) & $158(48.2 \%)$ \\
Antihypertensive treatment (\%) & $152(46.3 \%)$ \\
Macrohematuria (\%) & $143(43.6 \%)$ \\
Body weight $(\mathrm{kg})$ & $70.21 \pm 0.84$ \\
Height (cm) & $169.25 \pm 2.05$ \\
Body mass index (kg/m $\left.{ }^{2}\right)$ & $24.36 \pm 0.22$ \\
Serum creatinine (mg/d) & $1.51 \pm 0.07$ \\
Creatinine clearance (ml/min) & a \\
SBP (mmHg) & $80.40 \pm 2.0$ \\
DBP (mmHg) & $136.39 \pm 1.05$ \\
Urinary protein excretion (g/24 h) & $87.55 \pm 0.67$ \\
Follow-up from presentation (years) & $1.46 \pm 0.07$ \\
Follow-up from biopsy (years) & $11.36(4-23) \pm 0.38$ \\
Renal function loss (ml/min year) & $8.44(4-19) \pm 0.37$ \\
\hline
\end{tabular}

If not otherwise indicated, reported data are the ones collected at the time of renal biopsy. Presentation means the first recorded/reported episode of macrohematuria or microhematuria/proteinuria at urinalysis

${ }^{\text {a }}$ Computed with Cockcroft-Gault formula [24]

$p<0.001)$, hypertension $\left(R^{2}=0.103, p<0.001\right)$, serum creatinine $\left(R^{2}=0.036, p=0.001\right)$ at diagnosis and score of Lee et al. $\left(R^{2}=0.066, p<0.001\right)$ correlated significantly with renal function loss, while age of onset, serum IgA concentration, gender, and BMI did not. When all were included in a multiple regression model, only urinary protein excretion and hypertension at diagnosis gave an independent significant contribution to the model. The overall variance increased very little from that explained by proteinuria alone $\left(R^{2}\right.$ from 0.214 to 0.237 ), with only minimal contribution from hypertension at diagnosis $\left(R^{2}=0.023, p=0.002\right)$.

The frequencies of ADD1 ( $\alpha$-adducin) and ADD2 $(\beta$ adducin) genotypes are summarized in Table 2. Clinical characteristics according to ADD1 and ADD2 genotype are reported in Tables 3 and 4, respectively. Carriers of at least one ADD2 1797T allele had slightly higher blood pressure. The degree of renal function loss was affected by ADD2 (Table 4), but not by ADD1 genotypes (Table 3).

The ANOVA table for the model, considering ADD1 460Trp allele and ADD2 1797T allele dominant, is shown in Table 5. The $R^{2}$ for the model, including the effect of urinary protein excretion at diagnosis, was 0.245 . When only ADD1 and ADD2 genotypes and their interaction were included, the model remained statistically significant, though the variance explained was substantially lower $\left(R^{2}=\right.$ $0.057, p=0.0004)$. Note that also ADD1-ADD2 interaction was statistically significant $(p=0.0174)$.
Neither ADD1 nor ADD2 was associated to proteinuria. However, only in carriers of the adducin mutant alleles, ACE inhibitors significantly decreased the level of proteinuria (ADD1 460Trp $1.87 \pm 0.24$ versus $1.18 \pm 0.17 \mathrm{~g} / 24 \mathrm{~h}, p=0.02$; ADD2 1797T $1.96 \pm 0.2$ versus $1.14 \pm 0.17 \mathrm{~g} / 24 \mathrm{~h}, p=0.04$ ). Conversely, in carriers of the adducin wild-type alleles, ACE inhibitors did not affect proteinuria (ADD1 Gly460Gly $1.63 \pm 0.12$ versus $1.38 \pm 0.11 \mathrm{~g} / 24 \mathrm{~h}, p=0.15$; ADD2 C1797C $1.56 \pm 0.13$ versus $1.28 \pm 0.11 \mathrm{~g} / 24 \mathrm{~h}, p=0.13$ ).

To provide more information on the relationships between GFR loss per year, genotypes, and level of proteinuria at onset, these variables were analyzed with an additional linear model in which the degree of proteinuria was analyzed as tertiles, and least square means were obtained for the rate of renal function loss in each of these classes. The rate of renal function decline was more than double in carriers of the ADD1 460Trp + ADD2 1797T combination of genotypes $\left(-4.04 \pm 1.15 \mathrm{ml} \mathrm{min}{ }^{-1}\right.$ year $^{-1}$ per gram of urinary protein) than in carriers of the ADD1 Gly460Gly + ADD2 C1797C one $\left(-1.64 \pm 0.36 \mathrm{ml} \mathrm{min}^{-1}\right.$ year $\left.^{-1} ; p=0.005\right)$, with intermediate and similar values for the combinations where only one mutant adducin (either ADD1 or ADD2) genotype was present (Gly460Gly+1797T $-3.04 \pm 0.57 \mathrm{ml} \mathrm{min}^{-1}$ year $^{-1}$; 460 Trp + C1797C $-3.09 \pm 0.44 \mathrm{ml} \mathrm{min}^{-1}$ year $^{-1}$ ).

Glomerular immunohistochemical analysis for $\alpha$ - and $\beta$-adducin in IgA nephropathy Twenty IgAN patients, chosen for the availability of the material for immunohistochemistry, have been analyzed and divided into two groups according to the rate of renal function decline: stable renal function (nonprogressors) or rapidly progressing toward endstage renal failure (progressors). We did not find any difference in $\alpha$ - and $\beta$-adducin staining. The results of two representative patients are shown in the supplementary Fig. S10.

\section{Discussion}

The major findings described in the present work are (1) the localization of $\alpha$ - and $\beta$-adducin in glomerular podocytes in mice, rats, and humans; (2) in $\beta$-adducin null mice,

Table 2 Distribution of ADD1 ( $\alpha$-adducin) and ADD2 ( $\beta$-adducin) genotypes

\begin{tabular}{lccc}
\hline ADD1 & \multicolumn{3}{c}{ ADD2 } \\
\hline Gly460Gly & $231(70.4 \%)$ & C1797C & $217(66.2 \%)$ \\
Gly460Trp & $85(25.9 \%)$ & C1797T & $95(29.0 \%)$ \\
Trp460Trp & $12(3.7 \%)$ & T1797T & $16(4.9 \%)$ \\
\hline
\end{tabular}

Genotype frequencies are in Hardy-Weinberg equilibrium (test for deviation from Hardy-Weinberg: $p=0.826$ for ADD1 and $p=0.841$ for ADD2) 
Table 3 Baseline patient demographics, clinical and laboratory data according to ADD1 $(\alpha-$ adducin) genotype
If not otherwise indicated, reported data are the ones collected at the time of renal biopsy. Presentation means the first recorded/reported episode of macrohematuria or microhematuria/proteinuria at urinalysis

${ }^{\text {a }}$ Computed with CockcroftGault formula [24]

\begin{tabular}{llll}
\hline Variable & $\begin{array}{l}\text { Gly460Gly (231) } \\
\text { Mean (range) } \pm \text { SEM }\end{array}$ & $\begin{array}{l}\text { 460Trp (97) } \\
\text { Mean (range) } \pm \text { SEM }\end{array}$ & $p$ \\
\hline Age at presentation (years) & $31.5(16-77) \pm 0.91$ & $31.6(15-72) \pm 1.42$ & n.s. \\
Age at biopsy (years) & $34.8(16-77) \pm 0.95$ & $34.6(17-72) \pm 1.43$ & n.s. \\
Males (\% men) & $175(76 \%)$ & $72(74 \%)$ & n.s. \\
Hypertensive (\%) & $144(62 \%)$ & $44(45 \%)$ & n.s. \\
Antihypertensive treatment (\%) & $108(47 \%)$ & $44(45 \%)$ & n.s. \\
Macrohematuria (\%) & $94(41 \%)$ & $49(50 \%)$ & n.s. \\
Body weight $(\mathrm{kg})$ & $70.3 \pm 0.71$ & $70.1 \pm 1.02$ & n.s. \\
Height (cm) & $169.4 \pm 0.56$ & $168.8 \pm 0.76$ & n.s. \\
Body mass index (kg/m $\left.{ }^{2}\right)$ & $24.3 \pm 0.20$ & $24.5 \pm 0.32$ & n.s. \\
Serum creatinine (mg/dl) & $1.52 \pm 0.10$ & $1.47 \pm 0.08$ & n.s. \\
Creatinine clearance (ml/min) & $81.0 \pm 2.24$ & $79.0 \pm 3.90$ & n.s. \\
SBP (mmHg) & $135.8 \pm 1.20$ & $137.7 \pm 1.90$ & n.s. \\
DBP (mmHg) & $87.2 \pm 0.80$ & $88.5 \pm 1.22$ & n.s. \\
Urinary protein excretion (g/24 h) & $1.47 \pm 0.08$ & $1.46 \pm 0.15$ & n.s. \\
Follow-up from presentation (years) & $11.3(4-23) \pm 0.35$ & $11.4(4-23) \pm 0.55$ & n.s. \\
Follow-up from biopsy (years) & $8.3(4-19) \pm 0.30$ & $8.7(4-19) \pm 0.49$ & n.s. \\
Renal function loss (ml/min year) & $-5.04 \pm 0.42$ & $-6.46 \pm 1.00$ & n.s. \\
\hline
\end{tabular}

compared to wild-type controls, carrying the same polymorphic $\beta$-adducin variant (Q529R) as MHS rats, the expression of proteins of podocyte slit membrane or foot process cytoskeleton (such as phospho-nephrin, synaptopodin, $\alpha$-actinin, ZO-1, Fyn) is increased, while the urinary protein excretion was decreased. Therefore, the absence of $\beta$-adducin reduced the glomerular permeability to proteins. In contrast to erythrocytes [20], $\beta$-adducin deletion did not induce a loss of $\alpha$-adducin in glomeruli. (3) In congenic rats, the decreased expression of key podocyte proteins (such as nephrin, synaptopodin, $\alpha$-actinin, ZO-1, podocin, Fyn), followed by an increase of urinary protein excretion and glomerular damage, traveled together with the DNA segment containing the $\beta$-adducin polymorphism of MHS rats. This effect was blunted by the simultaneous presence of MHS $\alpha$-adducin. The epistatic interaction between $\alpha$ and $\beta$-adducin suggests that the glomerular changes observed here were very likely due to the adducin
Table 4 Baseline patient demographics, clinical and laboratory data according to ADD2 $(\beta-$ adducin) genotype

If not otherwise indicated, reported data are the ones collected at the time of renal biopsy. Presentation means the first recorded/reported episode of macrohematuria or microhematuria/proteinuria at urinalysis

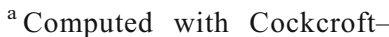
Gault formula [24]

\begin{tabular}{llll}
\hline Variable & $\begin{array}{l}\text { C1797C (217) } \\
\text { Mean (range) } \pm \text { SEM }\end{array}$ & $\begin{array}{l}\text { 1797T (111) } \\
\text { Mean (range) } \pm \text { SEM }\end{array}$ & $p$ \\
\hline Age at presentation (years) & $31.5(16-77) \pm 0.95$ & $31.6(16-72) \pm 1.31$ & n.s. \\
Age at biopsy (years) & $34.9(16-77) \pm 0.99$ & $34.4(16-72) \pm 1.33$ & n.s. \\
Males (\% men) & $168(77 \%)$ & $79(71 \%)$ & n.s. \\
Hypertensive (\%) & $99(46 \%)$ & $59(53 \%)$ & n.s. \\
Antihypertensive treatment (\%) & $94(43 \%)$ & $58(52 \%)$ & n.s. \\
Macrohematuria (\%) & $102(47 \%)$ & $41(37 \%)$ & n.s. \\
Body weight (kg) & $70.9 \pm 0.72$ & $68.9 \pm 1.00$ & n.s. \\
Height (cm) & $169.4 \pm 0.53$ & $168.8 \pm 0.80$ & n.s. \\
Body mass index (kg/m $\left.{ }^{2}\right)$ & $24.5 \pm 0.22$ & $23.9 \pm 0.27$ & n.s. \\
Serum creatinine (mg/dl) & $1.48 \pm 0.07$ & $1.56 \pm 0.16$ & n.s. \\
Creatinine clearance (ml/min) & $82.2 \pm 2.51$ & $76.9 \pm 3.02$ & n.s. \\
SBP (mmHg) & $134.8 \pm 1.12$ & $139.5 \pm 2.01$ & 0.041 \\
DBP (mmHg) & $86.6 \pm 0.78$ & $89.3 \pm 1.22$ & 0.054 \\
Urinary protein excretion (g/24 h) & $1.38 \pm 0.09$ & $1.63 \pm 0.13$ & n.s. \\
Follow-up from presentation (years) & $11.4(4-23) \pm 0.34$ & $11.3(4-21) \pm 0.58$ & n.s. \\
Follow-up from biopsy (years) & $8.4(4-19) \pm 0.24$ & $8.6(4-19) \pm 0.49$ & n.s. \\
Renal function loss (ml/min year) & $-4.77 \pm 0.41$ & $-6.82 \pm 0.92$ & 0.043 \\
\hline
\end{tabular}


Table 5 ANOVA for statistical model used to test effects of interactions among ADD1 $(\alpha$-adducin) and ADD2 ( $\beta$-adducin) genotypes

Dependent variable: eGFR loss $(\mathrm{ml} / \mathrm{min}$ year$)$

\begin{tabular}{lrrrrrr}
\hline Source & $\beta$ & std err $\beta$ & {$[95 \%$ Conf. Interval $]$} & $F$ value & $p$ value \\
\hline Proteinuria & -2.24 & 0.329 & -2.892 & -1.595 & 43.36 & $<0.0001$ \\
Follow-up after biopsy (years) & 0.27 & 0.098 & 0.083 & 0.471 & 7.94 & 0.0052 \\
$\alpha$-Adducin (460Trp allele dominant) & -0.15 & 1.091 & -2.301 & 1.994 & 4.27 & 0.0397 \\
$\beta$-Adducin (1797T allele dominant) & -4.66 & 1.490 & -7.594 & -1.728 & 8.28 & 0.0043 \\
Adducin interaction & 4.45 & 1.863 & 0.787 & 8.117 & 4.93 & 0.0092 \\
\hline
\end{tabular}

variations. (4) In human $\operatorname{IgAN}$, the rate of renal function decline increased when a specific combination of $\alpha$ - and $\beta$ adducin polymorphisms was present. Taken together, these observations strongly support the notion that $\alpha \beta$-adducin heterodimers are involved in the molecular mechanisms underlying the process of glomerular permeability, associated with an increase of protein excretion and progression rate of glomerular failure.

In human $\operatorname{IgAN}, \beta$-adducin polymorphism was associated to renal function decline, but not to the average urinary protein excretion, at least during the first 2 years after diagnosis. It is not clear whether this discrepancy with the rodent findings is real or due to the complexity of the human condition. In fact, in the human study, $47 \%$ of patients were on ACEI or other antihypertensive treatment. Renin-angiotensin system inhibition may differently affect proteinuria and progression toward renal failure [32] and may also differ across genotypes. In fact, the reduction of proteinuria associated to ACEI treatment was significant only in carriers of mutant ADD1 460Trp or ADD2 1797T alleles. It is worth mentioning that the cell surface expression of ACE is greater in human cultured fibroblasts carrying the ADD1 Trp allele, or in renal cells transfected with the ADD1 Trp allele, than in fibroblasts carrying the ADD1 Gly allele, or renal cells transfected with the ADD1 Gly allele [33]. These observations, taken together with the larger genetic heterogeneity of humans as compared to that of inbred strains of rodents and the difference in the adducin mutation sites, may account for the discrepancy between humans and rodents on the genotype-proteinuria relationship.

Nephrin is an essential component of the glomerular podocyte junction [34] and participates to the formation of the glomerular filtration barrier via interactions with associated proteins, including the Src family protein kinase Fyn [34-36]. Engagement of the nephrin ectodomain induces Fyn activation that favors nephrin phosphorylation [35] and the recruitment of adaptor proteins, such as Nck, involved in the regulation of podocyte junction formation and actin cytoskeletal dynamics [36]. Mutations of several podocyte proteins, or the knockout of Fyn or nephrin in mice, induce a rearrangement of the actin cytoskeleton and the disruption of the filtration barrier leading to renal disease $[3,4,36]$.
Recently, also $\beta$-adducin has been shown to be a specific target of Fyn [37]. Fyn binds and phosphorylates $\beta$-adducin at $\mathrm{Tyr}^{489}$, permitting its association with Fyn$\mathrm{SH}_{2}$ domain and translocation to the plasma membrane [37]. Interestingly, the polymorphism (Q529R) identified in the rat $\beta$-adducin C-terminal domain maps close to the Fyndependent phosphorylation residue $\left(\mathrm{Tyr}^{489}\right)$.

The data presented here in $\beta$-adducin null mice and congenic rats support the hypothesis that $\beta$-adducin may induce a reduction of Fyn protein expression on the cell membrane resulting in a downregulation of phosphorylated nephrin and related podocyte proteins, such as synaptopodin, ZO-1, and $\alpha$-actinin, associated with the appearance of glomerular podocyte damage and proteinuria. Conversely, the knockout of the $\beta$-adducin gene in mice, or the presence of the polymorphic $\alpha$-adducin variant in MHS, NA, or NAB rat substrains, seems to be protective. This effect appears to occur through the reactivation of the nephrin signaling pathway.

Limitations As a first point, with regards to the human studies, one should keep in mind that we used the Cockcroft-Gault formula to estimate the glomerular filtration rate. Though a suboptimal indicator, this formula is of practical use because it provides a quantitative estimate of the milliliters per minute loss of renal function in relation to the variables considered. Another note of caution concerns serum creatinine assay. Although creatinine had not been assayed by a unique unit, we respected center consistency, since each patient referred to his/her referring center that was using the same intracenter standards. A number of questions remain, however, unanswered. We have attempted to ascertain an association between a variety of genetic manipulations of adducin and the glomerular phenotypes. These include precise gene manipulations, like the knockout in mice, the introgression of DNA segments containing the adducin loci from one inbreed rat strain to another and genetic association studies in humans. Certainly, the introgression of a DNA segment, harboring other genes besides adducin [21], cannot exclude their influence on our findings. However, this weakness is tempered by the interaction between $\alpha$ - and $\beta$-adducin DNA segments. In fact, the possibility that the other genes, mapping in close vicinity to the adducin locus in the DNA fragment, display 
such an interaction on the phenotypes we have measured is unlikely in view of the biochemical requirement that $\alpha$ - and $\beta$-adducin function as heterodimers [6] and that both subunits are present in podocytes.

As in all the other studies aimed at establishing a putative relationship between a given gene variation and complex phenotypes, like progression of renal failure or proteinuria, when we change the context, we increase the number of confounding factors (such as variations in the genetic and environmental backgrounds) that may differently modulate the effect of the gene variants of interest. Therefore, we may anticipate some differences in the phenotype effect. Moreover, in our case, adducin mutations occur at different positions in rats and humans. In spite of the very high identity between the adducin of the two species $(92 \%)$ and the many protein function similarities between rat and human mutant variants [10], the difference in the mutation site may produce protein function variations that may differ across species.

Conclusions Genetic studies involve two major steps: (1) to demonstrate that a given gene is involved in the regulation of a phenotype and leads to disease (in our case, adducin and glomerular permeability) and (2) to define the mechanistic steps linking these gene variations to the clinical phenotypes. While we believe we have provided solid data to support the first step, the second one will require further investigation to explore the mechanism underlying the reduction of podocyte proteins that, in turn, affects the glomerular permeability to proteins.

The wide range of contexts explored here strengthens the conclusion that $\alpha$ - and $\beta$-adducins are involved in glomerular disease. We may speculate that the magnitude of the adducin polymorphism impact on glomerular disease of the individual patient may be modest, or more severe, according to the individual genetic-environmental background. Certainly, adducin genetic variants seem to exert a modifier rather than a triggering role within the heterogeneous network of the other podocyte gene polymorphisms.

Acknowledgment We thank Prof. D. Kerjaschki, Department of Pathology, Medical University of Vienna, for help in immunogold electron microscopy and $\operatorname{Dr} \mathrm{A}$. Corbelli for electron microscopy studies. The authors (MF, IM, CC, FP, FP) are Prassis sigma-tau employees and (GB) is a Prassis sigma-tau consultant.

Fundings This study was supported in part by a grant from the Telethon Foundation EC 861, FIRB2003 research grant RBLA038RMA-010 from the Italian Ministry of University and Scientific Research, by Ingenious Hypercare LSHM-CT-2006-037093 (DC), by HYPERGENES grant HEALTH-F4-2007-201550 (DC), and by National Institutes of Health, grant 1 R01 HL075714 (LLP).
Open Access This article is distributed under the terms of the Creative Commons Attribution Noncommercial License which permits any noncommercial use, distribution, and reproduction in any medium, provided the original author(s) and source are credited.

\section{References}

1. Wiggins RC (2007) The spectrum of podocytopathies: a unifying view of glomerular disease. Kidney Int 71:1205-1214

2. Aaltonen P, Holthofer H (2007) Nephrin and related proteins in the pathogenesis of nephropathy. Drug Discov Today Dis Mech 4:21-27 Renal diseases

3. Mathieson PW (2008) Podocyte-specific gene mutations are coming of age. J Am Soc Nephrol 19:190-191

4. Hinkes B, Vlangos C, Heeringa S, Mucha B, Gbadegesin R, Liu J, Hasselbacher K, Ozaltin F, Hildebrandt F, APN Study Group (2008) Specific podocin mutations correlate with age of onset in steroidresistant nephrotic syndrome. J Am Soc Nephrol 19:365-371

5. Tipping PG (2008) Are podocytes passive or provocative in proteinuric glomerular pathology? J Am Soc Nephrol 19:651-653

6. Matsuoka Y, Li X, Bennett V (2000) Adducin: structure, function and regulation. Cell Mol Life Sci 57:884-895

7. Tripodi G, Valtorta F, Torielli L, Chieregatti E, Salardi S, Trusolino L, Menegon A, Ferrari P, Marchisio PC, Bianchi G (1996) Hypertension-associated point mutations in the adducin alpha and beta subunits affect actin cytoskeleton and ion transport. J Clin Invest 97:2815-2822

8. Bianchi G, Tripodi G, Casari G, Salardi S, Barber BR, Garcia R, Leoni P, Torielli L, Cusi D, Ferrandi M, Pinna LA, Baralle FE, Ferrari P (1994) Two point mutations within the adducin genes are involved in blood pressure variation. Proc Natl Acad Sci 91:39994003

9. Cusi D, Barlassina C, Azzani T, Casari G, Citterio L, Devoto M, Glorioso N, Lanzani C, Manunta P, Righetti M, Rivera R, Stella P, Troffa C, Zagato L, Bianchi G (1997) Polymorphisms of alphaadducin and salt sensitivity in patients with essential hypertension. Lancet 349:1353-1357

10. Bianchi G (2005) Genetic variations of tubular sodium reabsorption leading to "primary" hypertension: from gene polymorphism to clinical symptoms. Am J Physiol Regul Integr Comp Physiol 289:R1536-R1549

11. Manunta P, Lavery G, Lanzani C, Braund PS, Simonini M, Bodycote C, Zagato L, Delli Carpini S, Tantardini C, Brioni E, Bianchi G, Samani NJ (2008) Physiological interaction between alpha-adducin and WNK1-NEDD4L pathways on sodium-related blood pressure regulation. Hypertension 52:366-372

12. Staessen JA, Wang JG, Brand E, Barlassina C, Birkenhäger WH, Herrmann SM, Fagard R, Tizzoni L, Bianchi G (2001) Effects of three candidate genes on prevalence and incidence of hypertension in a Caucasian population. J Hypertens 19:1349-1358

13. Wang JG, Staessen JA, Tizzoni L, Brand E, Birkenhäger WH, Fagard R, Herrmann SM, Bianchi G (2001) Renal function in relation to three candidate genes. Am J Kidney Dis 38:1158-1168

14. Nicod J, Frey BM, Frey FJ, Ferrari P (2002) Role of the alphaadducin genotype on renal disease progression. Kidney Int 61:1270-1275

15. Narita I, Goto S, Saito N, Song J, Ajiro J, Sato F, Saga D, Kondo D, Akazawa K, Sakatsume M, Gejyo F (2003) Interaction between $\mathrm{ACE}$ and ADD1 gene polymorphisms in the progression of $\operatorname{IgA}$ nephropathy in Japanese patients. Hypertension 42:304-309

16. Beeks E, van der Klauw MM, Kroon AA, Spiering W, Fuss-Lejeune MJ, de Leeuw PW (2004) Alpha-adducin Gly460Trp polymorphism 
and renal hemodynamics in essential hypertension. Hypertension 44:419-423

17. Merta M, Reiterová J, Stekrová J, Rysava R, Rihová Z, Tesar V, Viklický O, Kmentova D (2003) Influence of the alpha-adducin and ACE gene polymorphism on the progression of autosomal-dominant polycystic kidney disease. Kidney Blood Press Res 26:42-49

18. D'Amico G (1987) The commonest glomerulonephritis in the world: IgA nephropathy. Q J Med 64:709-727

19. Mackinnon B, Fraser EP, Cattran DC, Fox JG, Geddes CC (2008) Validation of the Toronto formula to predict progression in $\operatorname{IgA}$ nephropathy. Nephron Clin Prac 109:148-153

20. Gilligan DM, Lozovatsky L, Gwynn B, Brugnara C, Mohandas N, Peters LL (1999) Targeted disruption of the beta adducin gene (Add2) causes red blood cell spherocytosis in mice. Proc Natl Acad Sci 96:10717-10722

21. Tripodi G, Florio M, Ferrandi M, Modica R, Zimdahl H, Hubner N, Ferrari P, Bianchi G (2004) Effect of Add1 gene transfer on blood pressure in reciprocal congenic strains of Milan rats. Biochem Biophys Res Commun 324:562-568

22. Regele HM, Fillipovic E, Langer B, Poczewki H, Kraxberger I, Bittner RE, Kerjaschki D (2000) Glomerular expression of dystroglycans is reduced in minimal change nephrosis but not in focal segmental glomerulosclerosis. J Am Soc Nephrol 11:403412

23. Bartosik LP, Lajoie G, Sugar L, Cattran DC (2001) Predicting progression in IgA nephropathy. Am J Kidney Dis 38:728-735

24. Cockcroft DW, Gault MH (1976) Prediction of creatinine clearance from serum creatinine. Nephron 16:31-41

25. D'Amico G, Ragni A, Gandini E, Fellin G (1993) Typical and atypical natural history of IgA nephropathy in adult patients. Contrib Nephrol 104:6-13

26. Lee SM, Rao VM, Franklin WA, Schiffer MS, Aronson AJ, Spargo BH, Katz AI (1982) IgA nephropathy: morphologic predictors of progressive renal disease. Hum Pathol 13:314-322

27. Wang JG, Staessen JA, Barlassina C, Fagard R, Kuznetsova T, Struijker-Boudier HA, Zagato L, Citterio L, Messaggio E, Bianchi $\mathrm{G}$ (2002) Association between hypertension and variation in the $\alpha$ - and $\beta$-adducin genes in a white population. Kidney Int 62:2152-2159

28. Neter J, Wasserman W, Kutner MH (1985) Applied linear statistical models, 2nd edn. Irwin, Homewood
29. Brandis A, Bianchi G, Reale E, Helmchen U, Kühn K (1986) Age-dependent glomerulosclerosis and proteinuria occurring in rats of the Milan normotensive strain and not in rats of the Milan hypertensive strain. Lab Invest 55:234-243

30. Pugliese G, Ricci C, Iacobini C, Menini S, Fioretto P, Ferrandi M, Giardino LA, Armelloni S, Mattinzoli D, Rastaldi MP, Pugliese F (2007) Glomerular barrier dysfunction in glomerulosclerosisresistant Milan rats with experimental diabetes: the role of renal haemodynamics. J Pathol 213:210-218

31. Pugliese F, Mene' P, Cinotti GA (1986) Glomerular prostaglandins and thromboxane synthesis in normotensive and hypertensive rats of the Milan strain before and after development of hypertension. J Hypertension 4:S391-S393

32. Mann JF, Schmieder RE, McQueen M, Dyal L, Schumacher H, Pogue J, Wang X, Maggioni A, Budaj A, Chaithiraphan S, Dickstein K, Keltai M, Metsärinne K, Oto A, Parkhomenko A, Piegas LS, Svendsen TL, Teo KK, Yusuf S (2008) Renal outcomes with telmisartan, ramipril, or both, in people at high vascular risk (the ONTARGET study): a multicentre, randomized, double-blind, controlled trial. Lancet 372:547-553

33. Li Y, Zagato L, Kuznetsova T, Tripodi G, Zerbini G, Richart T, Thijs L, Manunta P, Wang JG, Bianchi G, Staessen JA (2007) Angiotensin-converting enzyme I/D and alpha-adducin Gly460Trp polymorphisms: from angiotensin-converting enzyme activity to cardiovascular outcome. Hypertension 49:1291-1297

34. Faul C, Asanuma K, Yanagida-Asanuma E, Kim K, Mundel P (2007) Actin up: regulation of podocyte structure and function by components of the actin cytoskeleton. Trends Cell Biol 17:428437

35. Verma R, Kovari I, Soofi A, Nihalani D, Patrie K, Holzman LB (2006) Nephrin ectodomain engagement results in Src kinase activation, nephrin phosphorylation, Nck recruitment, and actin polymerization. J Clin Invest 116:1346-1359

36. Jones N, Blasutig IM, Eremina V, Ruston JM, Bladt F, Li H, Huang H, Larose L, Li SS, Takano T, Quaggin SE, Pawson T (2006) Nck adaptor proteins link nephrin to the actin cytoskeleton of kidney podocytes. Nature 440:818-823

37. Gotoh H, Okumura N, Yagi T, Okumura A, Shima T, Nagai K (2006) Fyn-induced phosphorylation of beta-adducin at tyrosine 489 and its role in their subcellular localization. Biochem Biophys Res Commun 346:600-605 